\title{
COVID-19, Unemployment, and Behavioral Health Conditions: The Need for Supported Employment
}

\author{
Robert E. Drake ${ }^{1} \cdot$ Lloyd I. Sederer $^{2} \cdot$ Deborah R. Becker $^{1} \cdot$ Gary R. Bond ${ }^{1}$ (I) \\ Accepted: 16 March 2021 / Published online: 31 March 2021 \\ (c) The Author(s), under exclusive licence to Springer Science+Business Media, LLC, part of Springer Nature 2021
}

\begin{abstract}
The COVID-19 pandemic has caused massive unemployment, exacerbated pre-existing behavioral health (mental health and substance use) disorders for many people, and created new disorders for others. Although policy changes have increased health care and unemployment benefits, most people want jobs and self-sufficiency rather than handouts. A robust evidence base shows that supported employment can enable unemployed people with behavioral health conditions to find competitive, integrated employment and behavioral health supports. Millions of U.S. citizens may need these services as the pandemic recedes and jobs become available. Government attention to supported employment is necessary now more than ever.
\end{abstract}

\section{Background}

The COVID-19 pandemic is grievously harming U.S. citizens with behavioral health disorders, not only those with pre-existing serious mental illness but also those who have developed behavioral health conditions during the pandemic (Pfefferbaum \& North, 2020). COVID-19 infection and behavioral health conditions influence each other in a bidirectional relationship (Taquet et al., 2021). Recent reports from the CDC confirm rising rates of behavioral health symptoms, including anxiety, depression, traumatic stress, increased alcohol use, and suicidal ideation, among U.S. adults (Czeisler et al., 2020). Overall, 41\% reported at least one behavioral health condition, and more than $10 \%$ experienced serious suicidal thoughts. People of color and younger (18-44 years) people reported higher rates of behavioral health conditions.

Rising rates of unemployment also contribute to increasing behavioral health disorders (Paul \& Moser, 2009), leading to more suffering and deaths (Case \& Deaton, 2020). People who are unemployed have a higher rate of suicide (Blakely et al., 2003; Jin et al., 1995; Milner et al., 2013). And people with behavioral health conditions always suffer

Gary R. Bond

garybond@westat.com

1 Westat, Rivermill Commercial Center, 85 Mechanic Street Suite C3-1, Lebanon, NH 03766, USA

2 Columbia University School of Public Health, New York, USA more than others during such crises (Milner et al., 2014). Half or more of the people who have become unemployed during the COVID-19 pandemic have developed behavioral health conditions (Ganson et al., 2021; Panchal et al., 2020). Furthermore, people with behavioral health conditions are more likely to acquire COVID-19 infections and die than those without a behavioral health condition (Wang et al., 2021).

COVID-19 already has resulted in millions of Americans losing employment. Estimates range between 13 and 36 million, depending on different definitions and counting procedures (such as whether only wage earners are included or whether gig workers are counted) (Fields, 2020; Parker et al., 2020; Shierholz, 2020; U.S. Bureau of Labor Statistics, 2020). COVID-19, moreover, adds the stress of physical and social distancing. Women and people of color have been more severely impacted (Ewing-Nelson, 2020). While historically people of color have experienced higher unemployment rates than Whites, these disparities spiked in April 2020 and remained above pre-pandemic levels through the end of 2020, even as the overall unemployment rate has fallen (Wolfe \& Thomson-DeVeaux, 2021). Thus, the combination of a pandemic, unemployment, a behavioral health crisis, and diminished personal and community supports has created a multi-dimensional disaster. To recover, people will need security-food, housing, income, and social support-all of which derive from employment.

In response to the pandemic, the behavioral health field has expanded telehealth and other virtual communications (Druss, 2020; Moreno et al., 2020; Panchal et al., 2020); 
and federal, state, and local authorities have enacted several new policies (Goldman et al., 2020; Smith et al., 2020). As the COVID pandemic recedes, however, helping people to find jobs may be more effective than additional cash payments and may reduce disability applications. During and after a major recession, reemployment is especially difficult for people who have developed behavioral health conditions, and many, especially women, never return to previous levels of employment (Diby et al., 2021). Economists have estimated that almost one million unemployed workers applied for SSDI as a result of the Great Recession, and over 400,000 new beneficiaries joined the disability roles ( $9 \%$ of new beneficiaries between 2008 and 2012) (Maestas et al., 2018). The Social Security Administration should expect a deluge because disability applications rise rapidly when unemployment benefits end (Rutledge, 2012).

Unemployment can produce hopelessness and humiliation, while employment produces community and commitment to the common good (Sandel, 2020). Moreover, employment offers dignity, self-esteem, a positive identity, social connections, and a sense of purpose (Drake \& Wallach, 2020). As Nobel Laureates Banerjee and Duflo (2019) state, "work is not necessarily what follows after all the other problems have been solved and people are 'ready,' but is part of the recovery process itself." In other words, those impacted by the economic hardships spawned by a crisis need jobs, not continued handouts.

\section{Supported Employment}

As the COVID pandemic recedes in 2021, we can expect that many people, at least several million who have lost jobs, will have developed financial and behavioral health problems and will need a combination of health and vocational supports. Now is the time to plan services for these people. We know how to help them find jobs-and we know that employment is itself an effective behavioral health intervention (Drake \& Wallach, 2020).

The evidence-based approach to supported employment for people with behavioral health conditions is called individual placement and support (IPS). IPS links employment and behavioral health services, thereby assisting people to get the support to find jobs of their choice and the health care they need (Drake et al., 2012). IPS provides individualized job development and needed supports. Job choice and matching are key. For example, a younger client might want to be a caretaker for an elderly or disabled person; someone with severe social anxiety might prosper in a night job; and an animal lover may choose to be a dog walker. IPS employment specialists provide targeted job development and ongoing support to workers and employers for as long as needed and wanted. Job seekers find satisfying employment, and employers find good employees who have supports behind them.

As the length of time out of work increases, unemployed workers become increasingly discouraged (Nichols et al., 2013). Many give up on searching for work and the likelihood of their reemployment declines sharply (Kulik, 2001; Roelen et al., 2012). The IPS approach of rapid job search helps counteract this downward spiral of despair and inaction.

Twenty-eight randomized controlled trials have demonstrated that IPS supported employment programs, designed for people with a behavioral health condition, enable about two-thirds of participants in the U.S., including those with serious mental illnesses, substance disorders, and homelessness, to achieve employment, with many working steadily for years thereafter (Bond et al., 2020). IPS produces rates of employment, job tenure, and earnings that are two to three times higher than achieved with other interventions. Further, meta-analyses of four U.S. trials indicated that African Americans (nearly 50\% of the overall participants) and Latino Americans attained employment outcomes similar to those of Whites (Campbell et al., 2010, 2011). A large Social Security demonstration, the Mental Health Treatment Study, also showed that women and ethno-racial minorities achieved employment outcomes as good or better than those achieved by men and by Whites (Metcalfe et al., 2017, 2018).

\section{Supported Employment During the COVID-19 Pandemic}

We know that IPS supported employment has continued to help people with serious mental disorders find employment during the COVID-19 pandemic (see https://ipsworks.org). Current data from the IPS Employment Center on more than 20,000 people with behavioral health conditions each quarter show that many people with disabilities continue to gain competitive jobs. The competitive employment rate during the fourth quarter of 2020 (42.3\%) was approximately the same as the average over the past decade. This remarkable success has occurred because the IPS teams have continued to provide services remotely during the pandemic and have thus gained experience with providing all phases of supported employment with minimal face-to-face contacts.

Could remote IPS supported employment help workers displaced by COVID-19 return to meaningful employment? This is a critical question. We know that many of the millions displaced workers will need help returning to employment because their previous jobs may have disappeared, they will have been unemployed for a year or more, and at least half will have developed behavioral health conditions (not serious mental illnesses but anxiety, depression, 
post-traumatic stress, and excessive alcohol use) while unemployed.

Several lines of evidence point to remote IPS supported employment as a solution: First, studies of IPS for people with conditions other than serious mental illness have shown effectiveness (Bond et al., 2019). Second, studies of return to work interventions for people with depression are most effective when they combine vocational and behavioral health supports, which is a fundamental principle of IPS supported employment (Bond et al., 2017). Third, our current Social Security Administration study of unsuccessful disability applicants (few of whom have serious mental illness) in 30 cities across the U.S. (Riley et al., in press) has helped hundreds of people gain employment during COVID19. Fourth, our current study of veterans transitioning from the military to civilian life during COVID - many with anxiety, depression, and post-traumatic stress disorder-is showing that remote vocational supports can be effective (Bond et al., submitted). Finally, IPS employment specialists around the country have developed skills for and experience with remote delivery of all phases of supported employment. Their experience includes the important knowledge that remote IPS takes less time because it does not require meeting with clients and employers every day in the community, allowing for a greater number of clients on caseloads. Each of these examples incorporates most of the basic principles of IPS: e.g., attention to client preferences, rapid job search, targeted job development, ongoing support as needed after job acquisition, benefits counseling, and linking health and vocational supports.

Questions remain, of course. The COVID-19 unemployed workers with behavioral health conditions differ from the people with serious mental illnesses (schizophrenia, bipolar disorder, major depressive disorder) who need intensive IPS services. The needs of this new population for vocational and health supports are uncertain. How much IPS support will they need? How large a caseload can one employment specialist serve remotely? Do their work backgrounds confer advantages in terms of work skills? Have many already applied for disability? A simple pilot project could answer these and many other questions. Although most states report that they are expanding their Medicaid initiatives to address social determinants of health (Gifford et al., 2020), no expansion of supported employment has occurred.

\section{A Prescription for Action}

A crisis can produce positive outcomes. A moment in history as profoundly disruptive as we are undergoing as a consequence of COVID-19 (and its economic and social ramifications) demands that we expand IPS supported employment services. Millions of people are suffering and needing employment. We have the opportunity, now, to develop a solution to help people become employed and access needed behavioral health supports. Most people, including those with behavioral health conditions, want to work and can do so with minimal supports. Work is the best anodyne for unemployment but also for behavioral health conditions, costly human services, and disability (Drake \& Wallach, 2020).

The infrastructure to provide IPS supported employment remotely already exists in more than $80 \%$ of U.S. states (Pogue et al., 2021). At least 1,000 IPS supported employment programs are available in the U.S., and at least half of the states have developed infrastructure at the state level to support training, monitoring, and expanding these services (https://ipsworks.org). The Department of Labor's Office of Disability Employment Policy is currently helping other states to develop state-level collaborations (e.g., the VOICES and ASPIRE projects) and leading the Federal Interagency Commission on Supported Employment in exploring options with other federal agencies plus the Council of State Administrators of Vocational Rehabilitation, the National Association of State Mental Health Program Directors, and the IPS Employment Center. This Commission is critically important because we need all of these agencies to collaborate on increasing supported employment funding, training more employment specialists, and enhancing capacity throughout the U.S. Current capacity to provide supported employment remotely could be expanded quickly by adding employment specialists to existing teams to help the Americans who will need supports as COVID recedes. For millions of people, health and economic recovery may depend on action to expand services.

Funding This paper was written without any external funding support.

\section{Declarations}

Conflict of interests The authors declare that they have no conflicts of interest.

Ethics approval This paper did not include data collection involving human participants and therefore was not reviewed by an institutional review board

\section{References}

Banerjee, A. V., \& Duflo, E. (2019). Good economics for hard times: Better answers to our biggest problems. Penguin.

Blakely, T. A., Collings, S. C., \& Atkinson, J. (2003). Unemployment and suicide. Evidence for a causal association? Journal of Epidemiology and Community Health, 57, 594-600.

Bond, G. R., Al-Abdulmunem, M., Drake, R. E., Davis, L. L., Meyer, T., Gade, D. M., Frueh, B. C., Dickman, R. B., \& Ressler, D. R. 
(submitted). Transition from military service: Mental health and well-being among service members and veterans with serviceconnected disabilities.

Bond, G. R., Drake, R. E., \& Becker, D. R. (2020). An update on Individual Placement and Support. World Psychiatry, 19, 390-391.

Bond, G. R., Drake, R. E., \& Pogue, J. A. (2019). Expanding Individual Placement and Support to populations with conditions and disorders other than serious mental illness. Psychiatric Services, 70, 488-498.

Bond, G. R., Lerner, D. R., \& Drake, R. E. (2017). Work-focused interventions for depression (Final report). Assistant Secretary for Planning and Evaluation, Health and Human Services (https://aspe.hhs.gov/basic-report/work-focused-interventionsdepression-final-report).

Campbell, K., Bond, G. R., \& Drake, R. E. (2011). Who benefits from supported employment: A meta-analytic study. Schizophrenia Bulletin, 37, 370-380.

Campbell, K., Bond, G. R., Drake, R. E., McHugo, G. J., \& Xie, H. (2010). Client predictors of employment outcomes in highfidelity supported employment: A regression analysis. Journal of Nervous and Mental Disease, 198, 556-563.

Case, A., \& Deaton, A. (2020). Deaths of despair and the future of capitalism. Princeton University. https://doi.org/10.2307/j. ctvpr7rb2

Czeisler, M. É., Lane, R. I., Petrosky, E., Wiley, J. F., Christensen, A., Njai, R., Weaver, M. D., Robbins, R., Facer-Childs, E. R., Barger, L. K., Czeisler, C. A., Howard, M. E., \& Rajaratnam, S. M. (2020). Mental health, substance use, and suicidal ideation during the COVID-19 pandemic-United States, June 24-30, 2020. MMWR Morbiity and Mortality Weekly Report, 69, 1049-1057.

Diby, A. S., Lengagne, P., \& Regaert, C. (2021). Employment vulnerability of people with aevere mental illness. Health Policy, $125,269-275$.

Drake, R. E., Bond, G. R., \& Becker, D. R. (2012). Individual Placement and Support: An evidence-based approach to supported employment. Oxford University Press.

Drake, R. E., \& Wallach, M. A. (2020). Employment is a critical mental health intervention. Epidemiology and Psychiatric Sciences, 29(e178), 171-173. https://doi.org/10.1017/S204579602 0000906.

Druss, B. G. (2020). Addressing the COVID-19 pandemic in populations with serious mental illness. JAMA Psychiatry, 77, 891-892.

Ewing-Nelson, C. (2020, October). Four times more women than men dropped out of the labor force in September. National Women's Law Center Fact Sheet. https://nwlc.org/wp-content/ uploads/2020/10/september-jobs-fs 1.pdf.

Fields, S. (2020, October 12). How many people are unemployed right now? Marketplace (https://www.marketplace.org/2020/10/ 12/how-many-people-are-unemployed-right-now/).

Ganson, K. T., Tsai, A. C., Weiser, S. D., Benabou, S. E., \& Nagata, J. M. (2021). Job insecurity and symptoms of anxiety and depression among US young adults during COVID-19. Journal of Adolescent Health, 68, 53-56.

Gifford, K., Lashbrook, A., Barth, S., Hinton, E., \& Rudowitz, R. (2020). State Medicaid programs respond to meet COVID-19 challenges: Results from a 50-State Medicaid budget survey for state Fiscal Years 2020 and 2021. National Association of Medicaid Directors. http://files.kff.org/attachment/ExecutiveSummary-State-Medicaid-Programs-Respond-to-Meet-COVID19-Challenges.pdf .

Goldman, M. L., Druss, B. G., Horvitz-Lennon, M., Norquist, G. S., Ptakowski, K. K., Brinkley, A., Greiner, M., Hayes, H., Hepburn, B., Jorgensen, S., Swartz, M. S., \& Dixon, L. B. (2020).
Mental health policy in the era of COVID-19. Psychiatric Services, 71, 1158-1162.

Jin, R. L., Shah, C. P., \& Svoboda, T. J. (1995). The impact of unemployment on health: a review of the evidence. Canadian Medical Association Journal, 153, 529-540.

Kulik, L. (2001). Impact of length of unemployment and age on jobless men and women: a comparative analysis. Journal of Employment Counseling, 38, 15-27. https://doi.org/10.1002/j. 2161-1920.2001.tb00489.x.

Maestas, N., Mullen, K. J., \& Strand, A. (2018). The effect of economic conditions on the disability insurance program: Evidence from the Great Recession. National Bureau of Economic Research Working Paper 25338(http://www.nber.org/papers/ w25338). https://doi.org/10.3386/w25338

Metcalfe, J. D., Bond, G. R., \& Drake, R. E. (2017). Predicting employment in the Mental Health Treatment Study: do client factors matter? Administration and Policy in Mental Health and Mental Health Services Research, 44, 345-353. https://doi.org/ 10.1007/s10488-016-0774-x.

Metcalfe, J. D., Riley, J., McGurk, S., Hale, T., Drake, R. E., \& Bond, G. R. (2018). Comparing predictors of employment in Individual Placement and Support: a longitudinal analysis. Psychiatry Research, 264, 85-90.

Milner, A., Page, A., \& LaMontagne, A. D. (2013). Long-term unemployment and suicide: a systematic review and meta-analysis. PLOS ONE, 8(1), e51333. https://doi.org/10.51371/journal. pone.0051333.

Milner, A., Page, A., \& Lamontagne, A. D. (2014). Cause and effect in studies on unemployment, mental health and suicide: A metaanalytic and conceptual review. Psychological Medicine, 44, 909-917.

Moreno, C., Wykes, T., Galderisi, S., Nordentoft, M., Crossley, N., Jones, N., Cannon, M., Correll, C. U., Byrne, L., Carr, S., Chen, E. Y., Gorwood, P., Johnson, S., Kärkkäinen, H., Krystal, J. H., Lee, J., Lieberman, J., López-Jaramillo, C., Männikkö, M., ... Arango, C. (2020). How mental health care should change as a consequence of the COVID-19 pandemic. Lancet Psychiatry, $7,813-824$

Nichols, A., Mitchell, J., \& Lindner, S. (2013). Consequences of long-term unemployment. Washington, DC: Urban Institute (www.urban.org).

Panchal, N., Kamal, R., Orgera, K., Cox, C., Garfield, R., Hamel, L., Muñana, C., \& Chidambaram, P. (2020). The Implications of COVID-19 for mental health and substance use. abtcounseling.com.

Parker, K., Minkin, R., \& Bennett, J. (2020). Economic fallout from COVID-19 continues to hit lower-income Americans the hardest. PEW Research Center (https://www.pewsocialtrends.org/ 2020/09/24/economic-fallout-from-covid-19-continues-to-hitlower-income-americans-the-hardest/).

Paul, K. I., \& Moser, K. (2009). Unemployment impairs mental health: Meta-analyses. Journal of Vocational Behavior, 74, 264-282.

Pfefferbaum, B., \& North, C. S. (2020). Mental health and the COVID-19 pandemic. New England Journal of Medicine, 383, $510-512$.

Pogue, J. A., Bond, G. R., Drake, R. E., Becker, D. R., \& Logsdon, S. (2021). Growth of IPS supported employment programs in the US: An update (Unpublished manuscript, IPS Employment Center).

Riley, J., Drake, R. E., \& et al. (in press). Helping people denied disability benefits for an alleged mental health impairment: The Supported Employment Demonstration. Psychiatric Services.

Roelen, C. A., Norder, G., Koopmans, P. C., van Rhenen, W., van der Klink, J. L., \& Bültmann, U. (2012). Employees sick-listed 
with mental disorders: who returns to work and when? Journal of Occupational Rehabilitation, 22, 409-417.

Rutledge, M. S. (2012). The impact of unemployment insurance extensions on disability insurance application and allowance rates. Center for Retirement Research at Boston College (http:// crr.bc.edu).

Sandel, M. J. (2020). The tyranny of merit: What's become of the common good? Farrar, Straus, and Giroux.

Shierholz, H. (2020, September 25). Economic Policy Institute at least 33 million. Economic Policy Institute (https://www.epi. org/blog/).

Smith, T. E., Sullivan, A. M., \& Druss, B. G. (2020). Re-designing public mental health systems post-COVID-19. Psychiatric Services. https://doi.org/10.1176/appi.ps.202000400.

Taquet, M., Luciano, S., Geddes, J. R., \& Harrison, P. J. (2021). Bidirectional associations between COVID-019 and psychiatric disorder: retrospective cohort studies of 62,354 COVID-19 studies in the USA. Lancet, 8, 130-140. https://doi.org/10.1016/S22150366(20)30462-4.

U.S. Bureau of Labor Statistics. (2020). https://www.bls.gov/opub/mlr/ 2020/home.htm.

Wang, Q., Xu, R., \& Volkow, N. D. (2021). Increased risk of COVID19 infection and mortality in people with mental disorders: analysis from electronic health records in the United States. World Psychiatry, 20, 124-130.

Wolfe, J., \& Thomson-DeVeaux, A. (2021, February 5). How fast is the economy recovering? FiveThirtyEight (https://projects.fivethirty eight.com/us-economy-coronavirus/L.

Publisher's Note Springer Nature remains neutral with regard to jurisdictional claims in published maps and institutional affiliations. 